\title{
A Research of Blended Teaching Based on the Flipped Classroom Model Applies to Vocational Education --Experiment in the Major of Numerical Control Lathe
}

\author{
Jian-yong Lou ${ }^{1}$, Chen Jiang ${ }^{1}$, Pei-rong Zheng ${ }^{1}$, Zhen-pei Huang ${ }^{2}$ \\ ${ }^{1}$ College of Education and Science Technology, Zhejiang University of Technology, Hangzhou, China \\ ${ }^{2}$ Taizhou Technical School, Taizhou, China
}

Email address:

270821273@qq.com (Chen Jiang)

\section{To cite this article:}

Jian-yong Lou, Chen Jiang, Pei-rong Zheng, Zhen-pei Huang. A Research of Blended Teaching Based on the Flipped Classroom Model Applies to Vocational Education --Experiment in the Major of Numerical Control Lathe. Science Journal of Education.

Vol. 4, No. 2, 2016, pp. 73-77. doi: 10.11648/j.sjedu.20160402.19

Received: March 21, 2016; Accepted: March 31, 2016; Published: April 19, 2016

\begin{abstract}
The digital revolution developing swiftly in the world, it is the trend of the times to use technology in the education. The birth of flipped classroom perfect confirms this point. Under the background of vocational curriculum reform and using technology to improve the quality of secondary vocational education, the blended teaching mode is refreshing and has practical significance. In this paper, the hybrid-assembled advantages of "flipped class" and the traditional teaching, which brings new and fresh teaching experience for teachers and students. What's more, it can high-efficiency transports lots of high technicians for enterprise firm company, to keep in step with the times.
\end{abstract}

Keywords: Vocational Education, Flipped Classroom, Blended Teaching Model

\section{Introduction}

Education must adapt to the request of the era of talents, it need to reform continuously. The blended teaching mode used in the major of numerical control lathe in the area of secondary vocational education, not only can enrich teaching resources for teachers and students but also cultivate their self-learning ability, cooperative ability, management ability. This paper choices Taizhou technical school as an experimental point, the course and the data information root in there. The research simply prove that the blended teaching mode is suitable for vocational school, this teaching model still needs to much more deep study.

\section{The Secondary Vocational Student's Study Present Situation}

Significance of vocational education in today's society is to transport a batch of high-quality professional skilled personnel and high-quality social service providers.
Vocational education has been the focus of support objects. Various financial grants and various financial aid vocational schools want to be able to provide qualified social workers. However, to transport personnel and excellent social work is not easy; the most critical is to improve the quality of vocational education. Improve the quality of teaching first condition is interested students learned knowledge; this is the primary task of vocational education curriculum reform. However, from the existing state of view, vocational school learning atmosphere is not strong, traditional education has slightly weak pace, the results of the development of education needs to keep up with the times. In order to change the traditional teaching model and improve the students' learning interests to maximize the benefit of education. All of those eventually inspired the "flipped classroom" of intervention, and the combination of "traditional classroom" and "flipped classroom" teaching mode hybrid advantages resulting. Chinese style traditional teaching there are too many drawbacks, but 5,000 years of Chinese cultural heritage and historic traditional teaching methods witnessed the inevitable spread so far and rationality. Therefore, this article introduces 
the traditional teaching methods after extraction of the essence and removing the dross and "flipped classroom" teaching method combining hybrid-teaching model in vocational education and professional CNC applications.

\section{Flip the Classroom Intervention}

Flipped classroom also known as "reverse class" or "inverted classroom" flipped teaching sequence, after the change of the traditional classroom learning to teach for the first post-teaching, and the use of advanced information technology-assisted teaching. In the self-learning section before class, students learn according to the teaching resources provided by the teacher (video, audio, independent study before class task list, etc.) of new knowledge, in the form of these teaching resources no longer a single, which is unmatched by traditional teaching. There is no doubt that students are very receptive to these new and have fun learning nature. Independent Study section before class to take notes, mark do not know where, and for reporting in the classroom, so that teachers understand students' progress and to grasp the situation and make the appropriate adjustments classroom. In the classroom the next day, for group cooperative learning, can discuss, debate, do exercises and other activities to promote the internalization of the absorption of knowledge. Student is the protagonist of the classroom, the teacher's role more as a subsidiary, answering questions and classroom discipline managers. Flipped classroom in response to calls for education reform has brought new ideas to the classroom. As a humane classroom strategy to break the limitations of traditional teaching, so that students have more opportunity to experience, to promote understanding of knowledge, emphasis on learning and learning process, to promote students' self-learning ability and ability Practice conducive to long-term development of students. Flipped classroom structure shown in Figure 1.

\section{Self learning}

\section{Before class}

\section{Learning record In the class}

Communication

Answer questions

Review

Figure 1. Flip class structure.

\section{Based on Flip Class Blending Teaching Mode Is Put Forward}

With the rapid development of information technology, network teaching concept was put on the agenda, flipped classroom is typical of recent and Japanese popular these days, but as the witness time, people on the network education attributed to a rational, balanced the emerging online educational disadvantages, hybrid teaching model in this context came into being. The so-called hybrid teaching model is the traditional teaching of the inherited advantages of combined network teaching development of modern high technology brings, combined the two teaching mode. This will not only have inherited the traditional leading role of teachers in teaching -guidance, inspiration, supervision of teaching process also played a student initiative-autonomous learning, cooperative discuss difficult problems. In the tradition of study abroad, the blended learning model is divided into four major categories: conversion mode, elasticity mode, menu mode and enhanced virtual mode [1]. However, each model needs to mix and match, arbitrary choice, but most of the teachers and students of all ages or conversion mode. (Conversion mode flipped classroom also interspersed therein) hybrid teaching model shown in Figure 2.

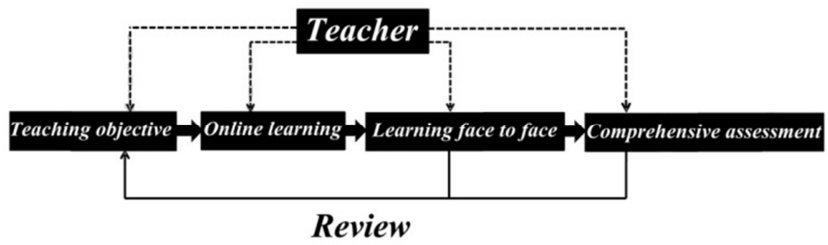

Figure 2. Framework of blending teaching model.

In addition, building a hybrid teaching model needs a variety of resource. There are: (1) teachers should both master the literacy ability and IT expertise, and must first work out the corresponding teaching objectives, then set out in detail the knowledge points, provide curriculum instructional videos, courseware and other types of multimedia teaching resources. (2) The school must have a network-teaching platform, network teaching platform is a carrier of the students, the students obtain teaching resources through the network teaching platform for learning exchanges. Once you have these resources, as shown flipped classroom built on the framework of a hybrid teaching model-teaching strategies Figure 3.

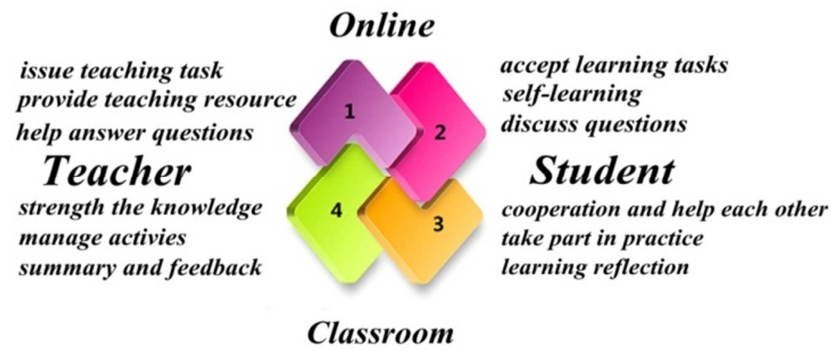

Figure 3. The construction of blending teaching strategy.

\subsection{Teacher Online Module}

Online module is a new mode of teaching should focus on prominent part, is the highlight of the teaching mode reform. 
First of all, teachers in the task of teaching arrangement should explicitly consider how student learning goals and objectives to enable students to complete independence. In the task form can be diversified (images, video, audio, essays, PPT, etc.) in order for students to individual choice. To spend a lot of hard work of teachers teaching task design. Teachers should always stand in the perspective of the students to think, learning content should be appropriate to grasp the degree of difficulty, some students do not have to strain to complete the self-study portion of this carefully controlled factor supporting arrangement exercises that also conform to Vygotsky "Zone of proximal development." Types of teaching resources are even more numerous, and a variety of learning materials links, regardless of national boundaries, regardless of region. This can not only broaden their horizons of knowledge, but also to promote students' interaction, mobilize their enthusiasm for learning. The most important point is that teachers and discuss the establishment of Q zone exchange zone on autonomous learning platform for between students' online discussions between teachers and the difficult point.

\subsection{Teachers in Classroom Module}

In the classroom, the teacher is leading role mainly in under the premise of a student-centered individualized student guidance and teaching. The role of the classroom teacher is the organizer, mentors and service providers, teachers use more heuristic teaching methods, discussion and conversational, emphasizing student body participation, focus on self-exploration and cooperation and exchange of students, teachers realize with students one on one personalized instruction [2].

Arrangements for classroom teachers in the task, but also take the initiative in the manager's role, as it will organize a number of activities to promote cooperation and exchange of students, the classroom atmosphere is definitely very active, but also to ensure that the classroom discipline. Teachers also do quiz record for future reference, and timely feedback between students and exchange, will learn to maximize efficiency.

\subsection{Students Online Module}

Dewey said, "Education process no purpose other than its own, it is their purpose." That is by now learning, so that students learn how to learn more and more willing to learn, to realize not taught to learn, to achieve lifelong learning [3]. After students online self-learning of new knowledge, make notes, if the new knowledge and understanding thorough enough, you can watch the video repeatedly re-learning. Then complete the other tasks of teachers arranged, for example, a number of supporting exercises and fun quiz. Unable to resolve the problems encountered can exchange forum for help teachers and other students. This will not only enhance the feelings of teachers but also students exercise the cooperation and exchange of students, the ability to help each other mutual assistance.

\subsection{Students in Classroom Module}

Students during the early part of the classroom teaching content should be the first independent study notes and jobs into the classroom summary report. Do not understand the difficult issues are gathered together, and finally by teachers FAQ. Between students before class on self-learning section did not understand the depth of knowledge of the content, so the student can be in the classroom in small groups to explore cooperation in the form of well-prepared teachers' heavy and difficult problems. Especially $\mathrm{CNC}$ professional, this practical course, each student is required to personally hands. Finally, the students have to do final summary in the classroom and carefully recorded for future reference as an evaluation.

\section{Carry Out Blending Teaching Model the NC Specialty in Secondary Vocational Schools}

According to the hybrid teaching model-building process, we are prepared based on the "NC programming and machining" course was the concrete realization. Based flipped classroom teaching mode hybrid we propose to implement the process presented in the following four stages:

\subsection{Integrating the Resource of Curriculum Modules}

Development of teaching tasks based on the teaching objectives. First, according to the syllabus prepared teachers to teach specific content, and with a full knowledge of the unit, and hybrid-teaching model, which is more livelihoods. Therefore, you must be a completely textbook knowledge in accordance with connective divided among a number of modules, each module subdividing into a number of complete knowledge, learning throughout the course structure shown in Figure 4.

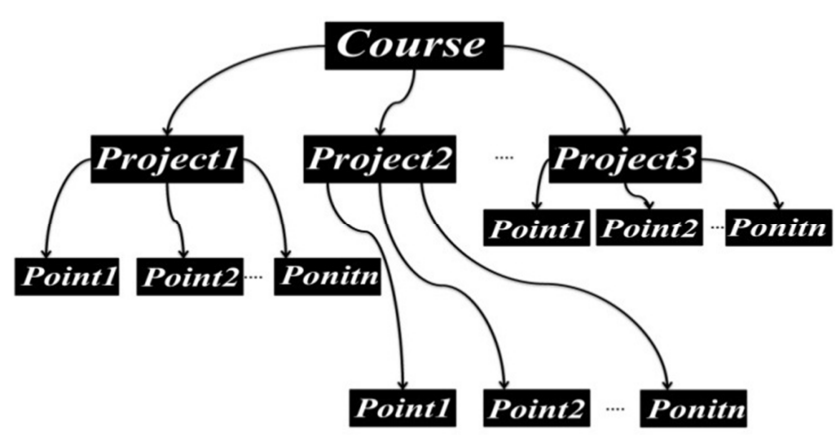

Figure 4. Curriculum structures about blending teaching model.

Based on the above ideas, to "NC programming and machining" to adjust the course content, the course content is divided into six modules, each module consists of a number of small dots of knowledge, to facilitate independent learning. Having a coupling between modules, each connected in series constitutes a complete system. Course structures as shown in Table 1. 
Table 1. Course structures.

\begin{tabular}{|c|c|c|}
\hline Teaching model & Knowledge point & content \\
\hline First degree fuel tank & Three & $\begin{array}{l}\text { Ex-circle, external thread, } \\
\text { outside slot processing }\end{array}$ \\
\hline $\begin{array}{l}\text { Second degree fuel } \\
\text { tank }\end{array}$ & Two & $\begin{array}{l}\text { Inner bore, inside slot } \\
\text { processing }\end{array}$ \\
\hline Third degree fuel tank & One & Thin-wall part machining \\
\hline $\begin{array}{l}\text { The rockets head parts } \\
\text { of model }\end{array}$ & One & Macro processor \\
\hline $\begin{array}{l}\text { The rockets tail parts } \\
\text { of model }\end{array}$ & Two & $\begin{array}{l}\text { Inside and outside } \\
\text { circular conical surface }\end{array}$ \\
\hline $\begin{array}{l}\text { The rockets booster } \\
\text { parts of model }\end{array}$ & One & $\begin{array}{l}\text { A cusp of outside circular } \\
\text { conical surface process }\end{array}$ \\
\hline
\end{tabular}

\subsection{The Construction of Network Teaching Resources}

Teachers teaching according to various forms of knowledge production of teaching resources teaching PPT, instructional videos, micro courses and collect knowledge and teaching network resources, the resources released in the online teaching platform for students to download and study. To further enhance students' learning enthusiasm, students will previous excellent reports, practice works plug on online teaching platform, presented to the students visit.

The construction of a teaching strategy based on the blended teaching to implement the teaching activities. Based on micro-channel public platform demonstration program once the teaching process, the process reflects the teacher, student activities and classroom teaching platform in the network, and the teaching process shown in Figure 5. As can be seen from Figure 5, during the implementation phase blended learning, students are the center of the learning process; teachers play a major role in guiding.

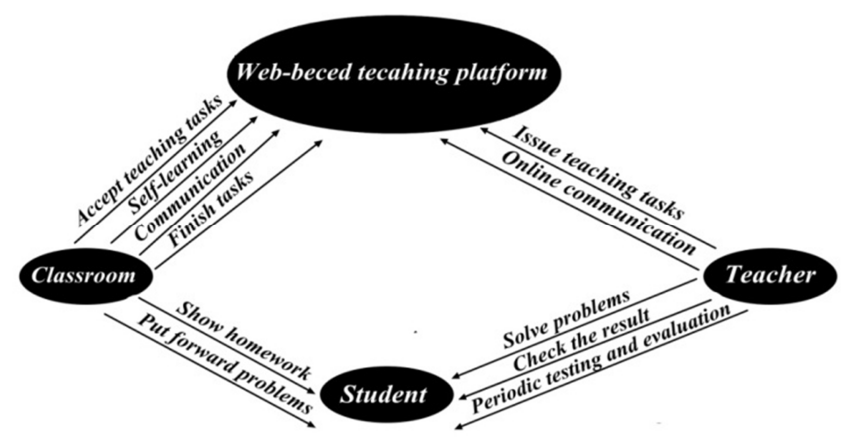

Figure 5. Courses implement process.

\subsection{Optimization of Students' Autonomous Learning}

There are too many shortcomings in the traditional teaching, because the teaching model is always teachers leading and students with patterns which causing some students to produce cynicism (do not want to learn, not learn, refused to learn). However, since flipped classroom joined, resolved this problem, people-oriented is the core concept of flipped classroom, it is student-centered and it changes students' passive role into active person image. The flipped classroom starts with interesting videos, pictures, animations and stories to attract students to take the initiative to explore new knowledges, and to identify problems, then solve problems, finally absorbed within the knowledge of the learned. Such a learning mode does not require teachers and parent's oppression, do not bring aversion for students. It solving students do not want to learn to solve the problem from the root.

Expand blended teaching model to burnish students' exchanges discussion session. In the past, those discussions are just the top students reported that the other students do not participate in the discussions, so there are a lot of ideas just in their minds nor speech, finally all of ideas died in silence. The new teaching model opened up a new world for students' discussions, students are free to play, and there published his own mission on purpose, but also to guide each other and discuss with classmates, or even debate, greatly improving student engagement, make the classroom more active, more profound memories. Fun, you will learn.

The so-called knowledge is to have school must ask, but for what they have learned to how to identify problems, ask questions and solve problems has been plagued by teachers and students, a few hundred thousand years, since ancient times. Hybrid flipped classroom-teaching mode to provide students with a special discussion area, there are many problems and answers, there is no time and geographical constraints, should read, in forums with classmates and teachers again depth exchanges. Such discretion and after thorough consideration, hard knowledge points and problems can be resolved and digested. In fact, these are for the students self-learning capabilities tailored.

\subsection{To Optimize the Teachers'Teaching Behavior}

Traditional teaching authority of the teacher's role is to teach, students only as passive bearers of knowledge, knowledge is always just a one-way transmission, teachers are too busy to take into account students' inner absorb new knowledge. However, with the development of the times, teachers haven't been allowed to go on like this capricious, not only to change their ideas, teachers' behavior also needs to improve. First of all, teachers should self-positioning, change from traditional teacher role to students' mentors, assistor and FAQ [4]. Implementation of blended teaching model, relieving teachers who need to do lectures insanely in the classroom, teachers can devote more time to go one on one guidance, individualized, let the strong execution and the poor students steady progress [5].

Teachers will use class time to organize more activities, active classroom atmosphere can bring a pleasant learning experience, and every classroom activity should arrange carefully and properly handled. The students are the main activities, teachers are facilitators' activities, there are difficult problems to help solve.

The most important thing is how to evaluate students' achievement, which is a heavy work of teachers. The new model not only cares about the best academic value, the usual class participation is also very important, what's more twenty-first centuries is to foster comprehensive development of talent, like teamwork and problem-solving ability should be included reference [6]. There are many dimensions of 
evaluation, academic performance is not the only measure. Therefore, making out a curriculum evaluation standard to suitable for courses is very important [7]. Of course, the evaluation results should be timely feedback to students and parents, in order to facilitate adjustment and make proper handling of common progress.

\section{The Blending Teaching Mode of Assessment Mode}

Traditional teaching assessment of student achievement includes: normal results, experimental results, and examination results. While jobs and attendance are the mainly factors considered in usually results, the experimental results mainly by the completion of the experiment, all three scores each accounted for a certain proportion, then get the final score [8]. If only depend on experimental results on the final word, it is difficult for students to make an objective and fair evaluation. After all, lab reports, assignments and models are likely to existed plagiarism phenomenon. To this end, we have added personal evaluation report, the results show, panel discussions, network or classroom's liveness of activities as evaluation criteria, making the evaluation more objective and accurate [9]. In figure 6, we can see the design of a comprehensive evaluation system.

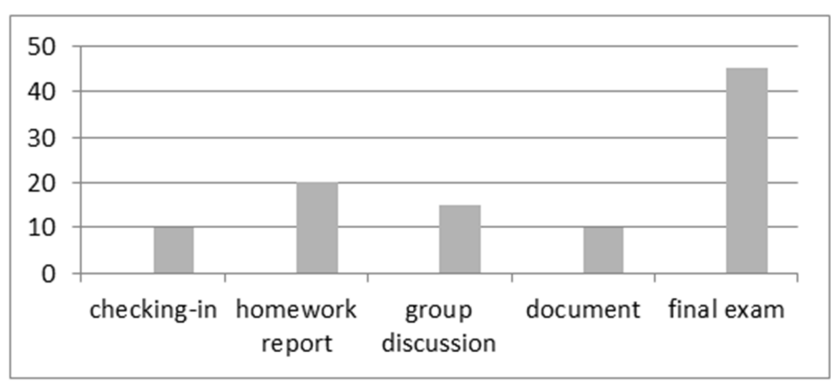

Figure 6. The course evaluation system.

\section{The Result Brought by the Blending Teaching Mode}

In the implementation of the hybrid-teaching model, teaching level of teachers has improved, the students' motivation to learn become stronger, students' interests in learning $\mathrm{CNC}$ lathe professional has improving significantly, and they are also actively participated in the classroom activities [10]. Objective and impartial of evaluation methods are to solve many contradictions and resentment among students. Of course, the education reform deeply needs the understanding and support of the government, schools, families and each community. Home-school teaching phenomenon is the one we all common pursuit.

\section{Conclusion}

Blended teaching model has a profound and lasting influence in academic world. However, if hybrid teaching model should be applied to consummate the point, for vocational schools, it is a great challenge. After all, it's just getting started, which will face a series of difficulties and setbacks. It requires continuous reflection and improvement, to maximize the effectiveness of teaching.

\section{References}

[1] Michael horn, heather. Blended learning [M]. Nie FengHua, $\mathrm{Xu}$ Tieying, eds. Beijing: mechanical industry publishing house, 2015.

[2] Dong-jiewang, Dai Weifen. American classroom "reverse" and its use in China [J]. The education theory and practice, 2014, (5): 42 to 45 .

[3] Luo Zubing Wen XiaoChuan. Learn the meaning of independence and its implementation [J]. Journal of global education prospects, 2013, (3): 35.

[4] Qi-liang zhang, Wang Aichun. Based on a new type of hybrid "flip" classroom teaching model research [J]. Journal of modern education technology, 2014, (4): 27-32.

[5] Jonathan Bergmann, Aaron Sims. Flip your classroom: reach every student in every class every day. Journal of Women's Health, 2012.

[6] Bettina Roesken. Hidden Dimensions in the Professional Development of Mathematics Teachers [M]. The Netherlands: Sense Publishers, 2011.

[7] Jon Baggaley, Reflection MOOC Postscript [J]. Distance Education, 2014, Vol. 35, No. 1, 126-132.

[8] Reeli Liivik. The Transformation of Vocational Education and Training (VET) in the Baltic States-Survey of Reforms and De-elopements [M]. Berlin: Springer Netherlands, 2006.

[9] Han Sik Shim, Gene L. Roth. Sharing Tacit Knowledge Among Expert Teaching Professors and Mentees: Considerations for Career and Technical Education Teacher Educators [J]. Journal of industrial teacher education, 2008, (4): 5-28.

[10] Fox, A Patterson, B. Software Engineering Curriculum Technology Transfer: Lessons learned from eBooks, MOOCs, and SPOCs, Splash Education Symposium [J]. In - Diana polis U. S. A, 2013(10). 